OPEN ACCESS

Edited by:

John Cook

George Mason University,

United States

Reviewed by:

Matthew Hornsey,

The University of Queensland,

Australia

Jennifer Peeples,

Utah State University, United States

${ }^{*}$ Correspondence:

Brittany Bloodhart

brittany.bloodhart@colostate.edu

† Janet K. Swim

orcid.org/0000-0002-3279-1308

Specialty section:

This article was submitted to

Science and Environmental

Communication,

a section of the journal

Frontiers in Communication

Received: 08 September 2018

Accepted: 20 December 2018

Published: 17 January 2019

Citation:

Bloodhart B, Swim JK and Dicicco E

(2019) "Be Worried, be VERY

Worried:" Preferences for and Impacts of Negative Emotional Climate Change

Communication.

Front. Commun. 3:63.

doi: $10.3389 /$ fcomm.2018.00063

\section{"Be Worried, be VERY Worried:" Preferences for and Impacts of Negative Emotional Climate Change Communication}

\author{
Brittany Bloodhart ${ }^{1 *}$, Janet K. Swim ${ }^{2 \dagger}$ and Elaine Dicicco ${ }^{2}$ \\ ${ }^{1}$ Department of Atmospheric Science, Colorado State University, Fort Collins, CO, United States, ${ }^{2}$ Department of \\ Psychology, The Pennsylvania State University, University Park, PA, United States
}

While communication experts largely recommend avoiding climate change messages that create negative emotional states, little is known regarding how members of the public use emotions in their own communication about climate change. Given the important role individuals can play in addressing climate change via their interpersonal communication, it is important to understand preferences for using or avoiding communication framed with negative emotions, and their ultimate impact on taking action to address climate change. Further, social expectations about the use of emotions may influence whether individuals' gender and political identity impacts their preference for using specific types of emotions. Three studies tested preferences for and impacts of three negative emotions common to climate change responses: fear, sadness, and anger, in comparison to messages framed without emotion. Findings indicate that people generally prefer messages framed without emotion, although in line with predictions, women, and Democrats are more apt to prefer emotional messages than men and Republicans. Although participants say they prefer messages framed without emotion, climate change messages framed with negative emotions are more likely than messages framed without emotion to match participants' feelings on climate change, while messages framed with specific types of negative emotions are more likely than messages framed without emotion to convey impressions of the speaker as rational, strong, and caring, which in turn predict greater preference for emotional over non-emotional messages. Further, results from a petition-signing study indicate that communicating with negative emotions does not promote nor hinder behavioral engagement.

Keywords: emotion, climate change, communication, gender, political identity, public activism

\section{INTRODUCTION}

Climate change can be an emotional topic due to the devastating effects it poses currently and in the future. The impacts on animals, natural spaces, and landscapes may evoke feelings of loss and sadness. The risks of continued and future impacts on people and essential resources may create fear, and frustration about humans not taking meaningful action may create anger at those who are perceived to block action or are indifferent. Decades of research indicate that emotions play a critical role in our attitudes, beliefs, decision-making, and behavior (e.g., see Schwarz, 2000), 
and there has been increasing recognition that emotions impact willingness to engage in collective action (e.g., Van Zomeren, 2013). For example, the cover of TIME magazine urged readers in 2006 to "be worried. Be VERY worried" about global warming (Kluger, 2006), while the documentary series "Years of Living Dangerously" showed viewers the frightening and devastating consequences of climate change (Cameron et al., 2014). However, communicating too much emotion may result in the message appearing "emotional" and lacking logic, exhaust the emotional resources of those it is meant to impact, or leave individuals without efficacy or motivation to respond. This was largely the thesis of Nordhaus and Shellenberger (2014), who opined in the New York Times that "global warming scare tactics" do little more than create further skepticism about the topic. Recommendations by communication and psychology researchers have largely followed suit, suggesting that fear appeals in particular be avoided when communicating about climate change (O'Neill and Nicholson-Cole, 2009; Shome and Marx, 2009).

However, studies on communicating climate change information with emotions (and in particular, with negative emotions) are still evolving, and are needed to understand how climate change is communicated by individuals and what the potential effects may be on engaging in climate action. Most research on emotions and climate change has focused on the use or inducement of emotions in communications directed at the public (e.g., Cismaru et al., 2011), but has not examined how members of the public choose to use emotions in their own communication. The latter is important when considering the critical role the public can play in addressing climate change via their interpersonal communication, their public expression of attitudes and beliefs, and their subsequent collective actions (Swim et al., 2018a), such as writing to public officials about the topic (Moyer et al., 2001). Individuals may want to express negative emotions to authentically convey feelings such as sadness, fear, or anger or to communicate urgency. This preference may also involve considerations about the benefits and costs of expressing negative emotions, such as self-presentation concerns about whether one would appear strong or weak, and effectiveness considerations such as whether emotions would interfere with the message appearing logical or being impactful.

The purpose of the present research is to examine individual preferences for the use of negative emotions in communication about climate change, and to assess whether expression of negative emotions in these forms of communication impacts others' willingness to also communicate about and take action on climate change. In this research we examine individuals' preference for using emotion in their own communication about climate change directed at a governmental agency (the EPA) and potentially the public (because participants are given the option to publicly post their comments online). Although research on public activism has explored how and why individuals choose to engage in behaviors such as communicating to political or media organizations, there has not, to our knowledge, been an examination of individuals' preference for using emotions in these types of communication, particularly on the issue of climate change. Thus, we drawn on research from mass communications, interpersonal communication, and social psychological theory about individual-level attitudes, beliefs, and emotions related to climate change to inform our understanding of this issue and frame our investigation.

\section{THE COSTS OF USING NEGATIVE EMOTION}

Much discussion about using emotions in climate change messaging has recommended avoiding negative emotions because of the potential unintended consequences of decreasing engagement on the issue. Compassion fatigue is one central argument against using negative emotions to engage the public on climate change. It has been argued that members of the public have a "finite pool of worry" when it comes to considering climate change, especially when compared to other social/political issues of concern (Hansen et al., 2004; Weber, 2010). Continual bombardment with negative emotions can result in emotional exhaustion or eventual desensitization (such as research showing that repeated exposure to violent video games diminishes empathy in viewers; Anderson et al., 2010). Research suggests that decrements in concern are a way for people to regulate the intense emotions they may feel when exposed to mass suffering (Cameron and Payne, 2011). For example, compassion for polar bears harmed by climate change is lessened when individuals focus on the suffering of an entire population as opposed to a single identified polar bear (Markowitz et al., 2013). Desensitization may similarly occur for repeated exposure to negative emotional messages about climate change, and diminish the beneficial effects of emotions on acting to address climate change. Further, dire messages about climate change can increase skepticism about the existence of climate change for those who hold strong just-word beliefs, and skepticism is related to decreased willingness to engage in environmental action (Feinberg and Willer, 2011).

Additionally, the use of emotions may undermine the perceived strength of one's argument. Even though emotions influence our everyday decisions and behaviors, they are frequently perceived to be illogical (Shields, 2002). Therefore, expressing emotion in reference to climate change may create the perception that one's position is not based on facts or logic, particularly given that climate change facts have come under fire in political and social discourse (McCright and Dunlap, 2011). Further, the perceived contrast between emotion and logic can lead to the perception that emotionally-framed messages about climate change are propaganda and antithetical to deliberative, analytic processing of persuasive information (Pratkanis and Turner, 1996). Thus, audiences may feel less defensive toward messages that are framed without emotion compared to messages that are perceived as deliberatively persuasive.

Although recommendations against the use of negative emotions have been based on research of mass communications toward the public (such as marketing campaigns), individuals may be persuaded to take a similar approach in their interpersonal communication about climate change. Specifically, 
those who wish to express negative emotions about climate change may hesitate because they have read warnings against doing so in popular media (e.g., see Engelhaupt, 2017), perceive that the use of emotions makes information appear illogical, or be concerned about undermining the effectiveness of the message. However, there may be important benefits to communicating about climate change with negative emotions, particularly in interpersonal communication, that we consider next.

\section{THE BENEFITS OF EXPRESSING NEGATIVE EMOTION}

Despite these potential costs, emotions are fundamental to decision making and behavior change, and the preferences for and benefits of their use in climate change communication warrants further study. First, emotions may help direct attention toward the issue of climate change. Negative emotional displays (e.g., anger) are more likely to receive attention than positive emotional displays (e.g., happiness; Rozin and Royzman, 2001), likely because emotional passion conveys concern and perceived importance (Parkinson, 1996), and information is more likely to be remembered when it is consistent with one's emotional state (Bower, 1981; e.g., climate change information framed with fear may resonate better with individuals who already feel fearful about climate change). Additionally, not expressing emotions may create the perception that even individuals who want to address climate change are not very concerned about the issue, which could decrease the perceived importance of the message (Czopp, 2013).

Second, a growing body of research framed with Protection Motivation Theory suggests that increased perceptions of threat can increase behavioral engagement on social and environmental issues, such as climate change (e.g., Floyd et al., 2000; Hornsey et al., 2015). For example, the more vulnerable individuals feel to the threats of climate change, the more likely they are to purchase electric cars (Bockarjova and Steg, 2014), take action to mitigate drought (Keshavarz and Karami, 2016), and be willing to engage in personal pro-environmental behaviors (Kim et al., 2013). While some research shows that negative framing of climate change information can produce a "boomerang" effect, particularly among those who are already predisposed to deny the impacts of climate change (i.e., conservatives; Hart and Nisbet, 2012), numerous studies indicate that when paired with information about how to address the threat, fear appeals can increase rather than decrease motivated behavior (Floyd et al., 2000; Moser and Dilling, 2011).

Third, emotions help to prompt and direct action (Ridderinkhof, 2017), such as toward sources of threat, and the expression of emotion has the potential to motivate action on climate change for oneself and others (e.g., taking an empathic perspective toward animals harmed by climate change increases financial support for environmental groups; Swim and Bloodhart, 2014). Individuals often assess their emotional orientation toward a specific topic when considering a behavioral response (Schwarz and Clore, 1996). Thus, messages that help individuals to pair their feelings on climate change with an emotional orientation (such as anger) may facilitate their likelihood of taking action to address it. Further, positive emotions may create complacency in regards to taking action to address climate change, as some negative emotions (shame and distress) have been more likely than positive emotions (hope) to prompt motivation to engage in climate change mitigation, (Hornsey and Fielding, 2016). Additionally, the use of emotions may help to spread communication about climate change to others. For example, messages framed with moral emotions are more likely to spread through social networks than those without emotional tones (Brady et al., 2017), with some types of emotions being more transmittable than others (e.g., angry messages are more likely to spread through social media than joyful or sad messages; Fan et al., 2014).

Fourth, regardless of their effects on others, people may feel a need to express their emotions about climate change, and suppression of these emotions may come at a personal cost. Emotional tone can be used to authentically communicate one's perceptions of reality (Higgins and Pittman, 2008) and individuals may desire to communicate this perception to others. For example, docents at local zoos and aquariums indicated that they felt uncomfortable with their inability to share the emotion they felt about climate change with visitors (Fraser et al., 2013). Suppressing emotions can interfere with cognitive tasks, increase stress, and ironically, increase intensity of the feelings (Richards and Gross, 1999; Dalgleish et al., 2009).

\section{EMOTIONS AND IMPRESSION MANAGEMENT}

Decisions about whether to use negative emotions in climate change communication go beyond beliefs about their effectiveness and personal benefits of expressing emotion to also include impression management (Schlenker, 1980). Emotional displays not only serve the function of communicating information about a situation (e.g., the importance of addressing climate change), but they also communicate information about the person displaying the emotion (e.g., the person is strong or caring; Hareli and Hess, 2010, 2012). When individuals are concerned with how they are perceived by others, they may alter their use or display of negative emotions (Flett et al., 1988). Negative stereotypes about environmentalists include characteristics such as "nagging" or "complaining" (Swim and Geiger, 2018) and being seen as "eccentric," "over-reactive" and "self-righteous" (Bashir et al., 2013), while "emotional” displays may be perceived as antithetical to logic (Shields, 2013). Thus, those who are concerned about climate change may want to manage the impression they make on others by restricting their use of emotions in climate change communication.

\section{Gender}

Social prescriptions about the display of emotion are highly gendered, and men in particular are expected to restrict their use of emotions (Rudman and Fairchild, 2004). Being "emotional" is a common stereotype about women (Fischer, 1993), and men experience a great degree of social pressure 
to be masculine and not feminine (O'Neil, 1981; Diekman and Eagly, 2000; Diekman and Goodfriend, 2006; Bosson et al., 2009). Further, gender differences in behavior have been attributed to social pressures to conform to sociallyenforced gender stereotypes and/or internalization of gender stereotypes (Diekman and Eagly, 2008). For example, men prefer climate change arguments that are framed with stereotypicallymasculine terms (e.g., those that involve leadership and business) over stereotypically-feminine terms (e.g., those that involve caring for others) because the latter are seen as "whiny" (Swim et al., 2018b). Thus, men may be more likely than women to avoid using emotions in climate change communication.

However, impressions of both men and women using emotion in communication about climate change likely depend upon the specific emotion displayed, as some emotions are seen as masculine and others are seen as feminine. Anger is stereotypically associated with men, while sadness and fear are stereotypically associated with women (Simon and Nath, 2004). Correspondingly, anger conveys agency whereas sadness conveys nurturance and fear conveys vulnerability (Hareli and Hess, 2010; Nelson, 2015; Wrede et al., 2015). Thus, men may be more likely than women to avoid displays of fear and sadness when communicating about climate change, but not necessarily to avoid anger. Women may be more likely to express fear or sadness than anger because they are stereotypicallyfeminine emotions, but because women do not experience the same pressure to avoid masculine attributes, they might not show a preference for one negative emotion over another in their communication about climate change. Consistently, women report feeling greater fear and sadness about climate change than men, although there are not gender differences in reported levels of anger (Swim et al., unpublished data). This possibility is also reflected in the finding that women are equally likely to select masculine or feminine arguments for climate change messages (Swim et al., 2018b).

\section{Political Identity}

The choice to express negative emotions related to climate change could also reflect the desire to "fit" with one's political identity. Political identity is not only related to beliefs about climate change (Hornsey et al., 2016), but also the emotional intensity of those beliefs. In the United States, Democrats and Independents are more likely to endorse the existence and urgency of addressing climate change compared to Republicans (Roser-Renouf et al., 2014), and Democrats are the most worried about climate change, followed by Independents and then Republicans (Dunlap, 2014). Communicating an emotional response to climate change may be perceived as communicating one's political identity (Fielding and Hornsey, 2016). Therefore, those who identify as Republicans may be more likely to restrict emotions when discussing climate change, while those who identify as Democrats or Independents may be more likely to express negative emotional responses, either because it is a genuine reflection of their concern, or they see emotional expression as a way to display their political identity.

\section{PRESENT RESEARCH}

The purpose of the present research was to better understand preferences for using negative emotions in personal climate change communication and to explore whether emotional framings influence individual willingness to address climate change. We studied three negative emotions common to climate change responses: fear, sadness, and anger, in comparison to messages framed without emotion. Study 1 examined whether individuals prefer to send a climate change message framed with one of the three emotions or a message that did not express emotion, and whether this preference differed as a function of gender or political identity. We predicted that women would be more likely to prefer emotional messages than men, particularly when they are framed with fear or sadness, while men may be more likely than women to prefer messages framed with anger. Study 2 explored the perceptions individuals have about communicating about climate change with or without negative emotions, and whether these impressions influence preference for emotional messages over non-emotional messages. Finally, Study 3 tested whether the use of these emotions in a message about climate change influenced individuals to support an EPA proposal on climate change compared to each other or to a message without emotion. Across all studies, we also assessed whether political identity influences the preferences for and responses to messages framed with emotions and whether these effects vary by the type of emotion conveyed. In addition, selection criteria was used to exclude participants who did not believe in climate change or who indicated that they opposed the message about climate change because we were interested in examining the preferences of communication among those who desire to communicate about climate change, rather than the comparison between those who support vs. oppose climate change mitigation. Further, the motives for choosing to communicate about climate change with or without emotion may be different for those who oppose the message altogether, and may have obscured any true effects among those who wish to communicate about climate change.

\section{STUDY 1}

The purpose of Study 1 was to examine which type of message framing people prefer in regards to climate change communication. Specifically, we explored whether people prefer to communicate a message about climate change framed with negative emotion vs. without emotion, and whether the type of emotion changes their preference. Because of different possible reasons for preferring emotional or non-emotional communication, we did not make directional predictions for these contrasts. However, we predicted that individuals would prefer messages that are framed with emotions that reflect their gender or political identity.

Hypothesis 1: Participants will prefer climate change messages that reflect their gender and political identities.

H1a: Women will be more likely than men to prefer messages that express fear and sadness about climate 
change, while men will be more likely than women to prefer messages that express anger or no emotion.

H1b: Democrats will be more likely than Independents, and Independents will be more likely than Republicans, to prefer to express negative emotions (fear, anger, sadness) about climate change.

\section{Materials and Methods Design}

The study consisted of a 2 (participant gender: female, male) X 3 (political party: Democrat, Republican, Independent) betweensubjects design. The dependent variable was preferred emotional framing of a message about climate change.

\section{Participants}

Two hundred and thirty seven U.S.-residing adults were recruited for the study through Amazon's Mechanical Turk and were paid $\$ 0.25$ for their participation. Six were excluded because they did not choose one of three major political party groups. Because we were interested in preferences regarding the types of framing for climate change messages and not whether participants wanted to convey a message, we excluded 34 participants who indicated they would not send any message because they were not in favor of the policy. While there were no gender differences in opting out of selecting a message, Republicans ( $n=15$, $35 \%)$ and Independents $(n=15,20 \%)$ were more likely than Democrats $(n=3,3.0 \%)$ to opt-out of selecting a message, $\chi^{2}$ $(2, N=219)=26.17, p<0.001$. In addition, we attempted to remove participants who did not pay attention during the study by calculating the median completion time ( $4.35 \mathrm{~min}$ ) among the remaining participants. This excluded an additional 36 participants who completed the survey in less than half the median completion time or more than two times the median completion time.

The final sample consisted of 161 participants living in the U.S (79 women and 82 men), with an average age of 34 (range 18 to 68 , median $=32$ ). The majority identified their race/ethnicity as White/Caucasian (80\%), while a minority identified as Black/African American (6\%), Asian (8\%), Latinx $(6 \%)$, or another racial/ethnic group (2\%). Half the sample indicated that they identified with the Democratic political party (52\%), while 35\% identified as Independent, and $13 \%$ as Republican. Participants leaned toward being liberal (16\% very liberal, 43\%, liberal, 29\% moderate, 9\% conservative, $4 \%$ very conservative). Most participants indicated concern about climate change based upon self-categorization into one of the Six Americas climate change opinion groups (38\% Alarmed, 42\% Concerned, 16\% Cautious, 4\% Disengaged, 1\% Doubtful; Maibach et al., 2009; Swim and Geiger, 2017). Most participants (78\%) had completed between some college, a 2-year degree, or a 4 -year college degree, and had a median annual income of between $\$ 30,000$ and $\$ 39,999$.

\section{Procedure and Measures}

Participants read a three sentence summary about the Environmental Protection Agency's (EPA's) proposal to reduce carbon pollution under the Obama administration, and were told that they would be allowed to comment on the proposal ${ }^{1}$. Next, they viewed a pre-written letter to the EPA, with a middle section where they could personally select specific sentences containing emotionally-framed statements, and told that their names and contact information would be posted publicly with their chosen comments. Participants were allowed to indicate that they would prefer to not choose any message options if they were not in favor of the EPA proposal. Participants then completed demographic questions and were debriefed about the true purpose of the study.

\section{Preferred emotion framing of the message}

Participants were asked to choose one of four responses about the Environmental Protection Agency's (EPA) proposal that contained either sadness, fear, anger, or no emotion framing. The four options all included the same statements, but described the writer as feeling either sadness, fear, anger, or no emotion (which used "I think" instead of "I feel"). The key emotion words were highlighted so that participants would be sure to notice the differences between the options. All four options were presented on the same page, and the order that they were presented in was randomized. The message text included the following, with the changes for the sad, fearful, angry, and no emotion messages appearing in that order (information not included in the brackets constitutes the no-emotion message:

"[I feel heartbroken/ frightened/ infuriated that] (I)in the last
century, we're causing sea levels to rise after not having them
change noticeably in the previous 2,000 years, putting many
countries at risk of existing in the near future. While there are
always changes in life on the planet, [it's sad/ scary/ absurd that]
our worldwide reliance on fossil fuels (coal, oil, and gas) will
accelerate the speed of environmental degradation that destroys
animals' habitats beyond their ability to adapt and increase
human illness such as asthma and Lyme disease. To be honest,
I [feel sad/afraid/angry about the] [think there are] serious
consequences for our future generations from the predicted rise
in global temperatures."

Full statements can be found in the Supplementary Materials.

\section{Gender and political identity}

Participants self-selected their gender ("female," "male," or "other/do not wish to respond") and political identification ("Republican," "Democrat," "Independent," "no party/not interested in politics," or "other").

\section{Results and Discussion}

We first examined preferences for the non-emotional vs. an emotional message using binary logistic regression with message preference as the dependent variable and participant gender and political identity as predictor variables. Participants in general were equally likely to choose the non-emotional message $(48 \%)$ as an emotional message (52\%: sad $=12 \%$; fear $=24 \%$;

\footnotetext{
${ }^{1}$ Participants were also told that the advisory council who would review the comments would be primarily female, primarily male, or equally female and male. However, analyses indicated that the gender make-up of the audience did not have an effect on message preference.
} 
anger $=16 \%)$, Wald $(d f=1)=0.24, p=0.63, O R=0.92$. Women were twice as likely as men to select a message that conveyed emotions ( $60 \%$ vs. $44 \%$, respectively) over the message that did not convey emotion, Wald $(d f=1)=4.83$, $p=0.03, O R=2.11$ [95\% CI: 1.08-4.10]. Although there was not a significant effect of political identity on preference for an emotional message over the non-emotional message, Wald $(d f=2)=2.83, p=0.24$, the trend was such that Democrats (54\%), and Independents (54\%) were more than twice as likely to select an emotional message over a non-emotional message than Republicans (38\%), OR = 2.30 [95\% CI: 0.84-6.33].

We then tested whether preference for the non-emotion message over each of the three emotion messages differed by participant gender. Results from a multinomial logistic regression, with participant gender as the predictor variable, indicated that, consistent with predictions, men were three times more likely than women to prefer the non-emotional message ( 56 vs. $40 \%$, respectively) over the sad message ( $7.3 \%$ vs. $16.5 \%$ ), Wald $(d f=1)=4.68, p=0.03, O R=3.39$ [95\% CI: $1.12-10.26$ ], and men were two times more likely than women to prefer the non-emotional message over the fear message (20.7 vs. $26.6 \%$ ), Wald $(d f=1)=3.28, p=0.073$, OR $=2.15$ [95\% CI: $0.94-$ 4.93], although the latter effect was only marginally significant. Gender differences in preferences for the non-emotional message over the anger message were not significant, nor were the effects of political party on preferences for the non-emotional message over any one of the specific emotion messages. Omnibus $X^{2}$ (3) $=6.60, p=0.09$.

The results of Study 1 provide evidence for the hypothesis that women and men may be engaging in impression management when making choices about whether to communicate about climate change with or without emotion, and about which negative emotions they prefer. Women were more likely than men to prefer emotional messages, and consistent with prior research suggesting that men avoid feminine emotions that are associated with caring for others, men were more likely to select the non-emotional messages over sad and fear messages than women.

The lack of effect of political identity on preferences for nonemotional vs. emotional messages may have been a result of the relatively few participants who identified as Republican, as this was conflated with their willingness to send the message to the EPA. In addition, it may have been difficult to detect effects for preferences among specific emotions because the number of people who preferred emotional messages was spread across three types of emotion. Therefore, we retest preferences for emotional vs. non-emotional messages in Study 2 with a larger sample size, use a continuous measure of preference, and tests preference for one of the emotion messages over the non-emotional message using a between-subjects design.

\section{STUDY 2}

The primary purpose of Study 2 was to better understand the reasons for individuals' preference for communicating about climate change with negative emotions vs. without emotion. Given the potential costs and benefits for using negative emotions in climate change communication, we explored whether beliefs about persuasiveness, the need to express/match one's own feelings, and management of impressions of the speaker of the message influenced preference for a message about climate change framed with anger, fear, sadness, or no emotion. Specifically, we tested whether using negative emotions in climate change messages create impressions of the speaker of that message as caring, strong, or rational, and whether these impressions influence whether or not individuals prefer to use emotions. In addition, we aimed to clarify potential effects from Study 1 by testing a larger sample, directly comparing each of the emotions to a non-emotional message, and including a more powerful measure of preference.

We first examined whether perceived persuasiveness, matching of feelings, and impressions of the speaker would influence preference for one of the emotionally-framed messages over the non-emotional message. We made the following hypotheses:

H1: Perceived persuasiveness, matching of feelings, and impressions of the speaker of the emotional message will predict preference for the emotional message over the nonemotional message.

H1a: The more persuasive the emotionally-framed message is perceived to be, the more participants will prefer the emotional message over the non-emotional message.

H1b: The more the emotionally-framed message matches the participants' feelings about climate change, the more they will prefer the emotional message over the nonemotional message.

H1c: The more the speaker of the emotionally-framed message is perceived as strong, caring, and rational, the more participants will prefer the emotional message over the non-emotional message.

We then tested factors that could predict whether emotionallyframed messages were seen as persuasive, matched one's feelings, and conveyed positive impressions of the speaker. As in Study 1 , we examined the role of type of emotion, participant gender, and political identity in predicting these preferences. One reason participants may prefer non-emotion messages more than emotionally-framed messages is that expressing emotion can be perceived as lacking rationality (Shields, 2002). Further, the specific emotions used may differ in the impressions they form, such that, consistent with expected gender differences (Simon and Nath, 2004) and traits associated with men and women (Diekman and Eagly, 2000), anger may make greater impressions of a speaker's strength, while sadness and fear may make greater impressions about the amount the speaker cares about climate change. Thus, we test whether emotion framing predicts impressions, and whether impressions mediate the relationship between emotion framing and preference:

H2: The type or presence of emotion used in messages will influence participants' impressions of the speaker of the message and subsequently their preference for the emotion message. 
H2a: The emotionally-framed messages will be seen as more irrational than rational compared to the nonemotional message.

H2b: The message framed with anger will be seen as more strong but less caring than the messages framed with sadness or fear.

H2c: Impressions of the speaker of the message will mediate the relationship between emotion-framing of the message and preferences for the emotional message.

Because the expression of emotion is highly gendered and socially regulated, we anticipated that impressions of the speaker of the message (i.e., as strong or caring) might predict more or less preference for the message depending upon the participant's gender. That is, the gendered effects found in H1a from Study 1 might be explained by the fact that men are more likely to prefer messages that create the impression of strength, while women are more likely to prefer messages that create the impression of caring.

H3: The gender of the participant will influence the degree to which participants' impressions of the message predicts their preference for the message.

H3a: Men will be more likely than women to prefer the emotional message when they perceive the speaker of the message as strong.

H3b: Women will be more likely than men to prefer the emotional message when they perceive the speaker of the message as caring.

In order to retest the non-significant pattern found in $\mathrm{H} 1 \mathrm{~b}$ of Study 2, we retested the effects of political identity on preferences and explored why political identity might influence emotionally-framed messages. However, unlike gender, political identity is not necessarily associated with stereotypes about certain emotions over others, and thus we expected that participants' political identity would be related to whether messages framed with emotion match their feelings about climate change, rather than their impressions of the speaker of the message, and that matching of one's feelings would mediate the relationship between political identity and preference for emotionally-framed messages. Although we do not make specific predictions about whether specific types of emotions will be more likely to match participants' feelings based on their political identity, we also explore these potential differences.

H4: The political identity of the participant will influence the degree that the emotionally-framed message matches their feelings about climate change and therefore will indirectly predict their preference for the emotionally-framed message over the message framed without emotion

H4a: Democrats and Independents will be more likely than Republicans to indicate that the emotional messages match their feelings compared to the non-emotional message.

H4b: The extent to which the emotional message matches participants' feelings will mediate the relationship between political identity and preference for the emotion over the non-emotion message.

\section{Measures and Methods \\ Design}

The study employed a 2 (participant gender: female, male) X 3 (political party: Democrat, Republican, Independent) $\times$ 3 (modified type of emotional framing of message: sadness, fear, anger) between-subjects design. The dependent variables were impressions of the emotional message and its author, preference for the emotional over the non-emotional message, and choosing to submit the emotional message over the nonemotional message to the EPA.

\section{Participants}

Six hundred and ten participants living in the United States who indicated that they were Alarmed, Concerned, or Cautious about climate change were paid $\$ 1.00$ to complete the study online through Amazon's Mechanical Turk. A pre-screening survey restricted participants who had participated in any other study related to this research, and allowed us to admit the same number of women and men to take the survey, although 20 participants were excluded for providing different gender identities on the pre-screening than on the survey itself. After reading the messages, participants indicated whether they would be likely to submit one of the messages to the EPA or to submit a comment in opposition to the clean power plan. Participants who indicated that they would not submit a message or submit an opposition message were also excluded $(n=76)$. After excluding these participants, the median completion time was $7.29 \mathrm{~min}$. Like Study 1, those who completed the study in less than half the median time or more than twice the median time were also dropped from the analyses $(n=98)^{2}$.

The final sample consisted of 416 participants living in the U.S (208 women and 208 men), with an average age of 38 (range 19 to 79 , median $=34$ ). The majority identified their race/ethnicity as White/Caucasian (78\%), while a minority identified as Black/African American (8\%), Asian (8\%), Latinx (7\%), or another racial/ethnic group (3\%). Half the sample indicated that they identified as Democrat (50\%), while 28\% identified as Independent, and $17 \%$ as Republican. Most participants (75\%) had completed between some college, a 2-year degree, or a 4year college degree, and had a median annual income of between $\$ 30,000-\$ 39,999$.

\section{Procedure}

Participants read the same policy statement by the EPA as in Study 1 on their proposed "Clean Power Plan," and were told that the EPA provides an open period for public comments. They were then told that some groups provide pre-written statements for the public to modify and send to the EPA if they wish. Participants were provided with the "original" version of the

\footnotetext{
${ }^{2}$ Although participants were recruited based upon having indicated that they were Alarmed, Concerned, or Cautious about climate change, 17 participants indicated at the end of the survey that they were Disengaged, Doubtful, or Dismissive of climate change. These participants were not excluded from the study because they indicated in the survey that they would have submitted either the original or modified message to the EPA.
} 
statement in support of the EPA's plan, which contained no emotion, and used "I think" to indicate opinions. Directly below, participants were provided with a "modified" version of the statement, which they were told was written by a member of the public, and used emotional wording, including "I feel" to indicate opinions. The modified version either contained sad, fearful, or angry emotions, and the statements were the same as those used in Study 1. As in Study 1, the differences between the two statements were underlined so that they were obvious to participants. The modified version of the statement served as the experimental manipulation of the study, and participants were randomly assigned to condition.

After viewing the "original" (no emotion) and "modified" (either sad, fear, or anger emotion) message, participants were asked to write a short description of the difference between the statements, and then compare the two. Specifically, they rated whether the original or modified statement was more persuasive, better matched their own feelings about climate change, and which of the two statements they preferred. They also answered questions about their impression of the person who made the modified statement. Finally, participants were asked whether they would be more likely to submit the original (no emotion) or modified (emotion) version of the statement to the EPA, completed demographic questions, and debriefed about the purpose of the study.

\section{Measures}

\section{Persuasiveness of message}

Participants used a sliding scale from 0 (not at all) to 100 (very much) to indicate whether the modified (emotion) statement was (1) "more persuasive," (2) "more convincing in conveying the need for the policy," and (3) "less effective" (reverse-coded) than the original (no emotion) statement, on a scale from 0 to 100 , Cronbach's $\alpha=0.92$.

\section{Matching of feelings}

Participants used a sliding scale from 0 (not at all) to 100 (very much) to indicate the amount they agreed with five items about whether the modified (emotion) statement accurately reflected their feelings. Items were "the modified comment conveys my feelings about climate change," "the modified comment does NOT convey my feelings about climate change" (reverse-coded), "the emotions expressed in the modified comment match my emotions," "the emotions expressed in the modified comment do NOT match the way I feel" (reverse-coded), and "the modified comment overstates the intensity of my feelings compared to the unmodified comment" (reverse-coded). Higher values indicate that the modified statement matches the intensity of the participants' feelings, Cronbach's $\alpha=0.92$.

\section{Impression of modification author}

Participants were asked to provide their "impression of a person who would make this modification" along three primary dimensions: rationality, strength, and care. All comparisons were made on an 11-point scale (-5 to "strongly disagree" to 5 "strongly agree," using the following items at each end of the scales. Rationality of the author was measured with three items: eccentric vs. reasonable; irrational vs. rational; and overactive vs. calm, Cronbach's $\alpha=0.91$. Strength of the author was measured with three items: weak vs. strong; frail vs. powerful; and timid vs. courageous, Cronbach's $\alpha=0.92$. Caring of the author was measured with three items: insensitive vs. caring; indifferent vs. sympathetic; and uncompassionate vs. compassionate, Cronbach's $\alpha=0.92^{3}$.

\section{Preference for message}

Preference for the emotional over the no-emotion statement was measured by asking participants the degree to which they (1) "like," (2) "are comfortable with," and (3) "are hesitant about the modified vs. the original comment" on an 11-point scale ( -5 "original" to 5 "modified" with 0 indicating "neutral"), Cronbach's $\alpha=0.92$. Thus, values below zero indicate preferences for the no-emotion message and values above zero indicate preferences for the message modified to include emotions.

\section{Gender and political identity}

Participants self-selected their gender and political identification with the same measures used in Study 1.

\section{Results}

We examined the descriptive statistics for all variables included in the analyses, comparing outcomes for each type of emotional message to the non-emotional message, and then the average of all emotional messages vs. the non-emotional message. Means and standard errors are presented in Table 1. We conducted $t$ tests comparing means to the mid-point of each measure in order to test evaluations of the emotional (modified) message to the non-emotional (original) message. In general, participants saw the message framed with emotion as significantly more persuasive, reflective of their feelings, and the author of the message as significantly more caring, strong, and rational than the non-emotional message. This was true for all of the specific types of emotions compared to the no-emotion message except in the case of anger vs. no-emotion on perceived rationality of the author, for which participants did not perceive the emotion or no-emotion message as being more rational. However, contradictorily, participants preferred the non-emotional message over any of the emotionally-framed messages. This finding is further fleshed out in the analyses below.

We also used a univariate ANOVA with a Bonferonni correction for the post-hoc tests to examine whether the type of emotion message predicted different impressions and preferences for the emotion message over the no-emotion message (also Table 1). The type of emotion message did not influence impressions of whether the message was persuasive, matched participants' feelings, or overall preference for the message. However, the anger message was seen as significantly less caring

\footnotetext{
${ }^{3}$ Participants also indicated whether they expected the author of the message to be man vs. woman, Democrat vs. Republican, liberal vs. conservative, and nonwhite vs. White. Although the speaker of the message framed with anger was perceived as more likely to be a man than a woman, this did not mediate the relationship between the emotion type and perceived rationality or strength of the message. There were no differences between whether the author was perceived to be a Democrat vs. Republican, liberal vs. conservative, or non-white vs. White.
} 
TABLE 1 | Average perceptions of emotional messages compared to the non-emotional message.

\begin{tabular}{|c|c|c|c|c|}
\hline Variable & $\begin{array}{l}\text { All Emotion vs. } \\
\text { No emotion }\end{array}$ & $\begin{array}{l}\text { Sad vs. No } \\
\text { emotion }\end{array}$ & $\begin{array}{c}\text { Fear vs. No } \\
\text { emotion }\end{array}$ & $\begin{array}{c}\text { Anger vs. No } \\
\text { emotion }\end{array}$ \\
\hline & Mean (SE) & Mean (SE) & Mean (SE) & Mean (SE) \\
\hline Persuasive $^{1}$ & $58.71(1.43)^{\star}$ & $59.40(2.39)^{\star a}$ & $60.48(2.52)^{\star a}$ & $56.11(2.54)^{\star a}$ \\
\hline $\begin{array}{l}\text { Match } \\
\text { feelings }{ }^{1}\end{array}$ & $59.83(1.28)^{\star}$ & $63.44(2.13)^{\star a}$ & $58.58(2.25)^{\star a}$ & $57.02(2.27)^{\star a}$ \\
\hline Rational $^{2}$ & $0.24(0.12)^{\star}$ & $0.74(0.21)^{\star \mathrm{a}}$ & $0.74(0.20)^{\star a b}$ & $-0.31(0.21)^{b}$ \\
\hline Caring $^{2}$ & $2.52(0.10)^{\star}$ & $3.06(0.16)^{\star a}$ & $2.62(0.17)^{\star a}$ & $1.81(0.17)^{\star \mathrm{b}}$ \\
\hline Strong $^{2}$ & $1.01(0.12)^{\star}$ & $0.76(0.20)^{\star \mathrm{a}}$ & $0.53(0.21)^{\star a}$ & $1.77(0.21)^{\star b}$ \\
\hline Preference ${ }^{3}$ & $-0.93(0.15)^{\star}$ & $-0.79(0.26)^{\star a}$ & $-0.86(0.27)^{\star a}$ & $-1.17(0.27)^{\star a}$ \\
\hline
\end{tabular}

*Indicates that the mean is significantly different from the midpoint of the scale, using a t-test with a 95\% confidence interval.

${ }^{a, b}$ Means with different letters within row are significantly different from each other, using an ANOVA to test emotion type on each outcome, with a Bonferroni correction for paired comparisons, $p<0.05$.

${ }^{1}$ Scores indicate the extent to which the emotional message was more likely to have the characteristics than the non-emotional message: 0 (not at all) to 100 (completely), with a midpoint of 50 .

${ }^{2}$ Scores indicate that extent to which the emotional message conveyed the impression more so than the non-emotional message:-5 (strongly disagree) to 5 (strongly agree), with a midpoint of 0 .

${ }^{3}$ Scores indicate preferences for non-emotional message $(-5)$ to preferences for the emotional message (5), with a midpoint of 0.

than the sad or fear message, $F_{(2,411)}=14.91, p<0.001$, $\eta_{p}^{2}=0.07$, but more strong than the sad or fear message, $F_{(2,411)}=9.82, p<0.001, \eta_{p}^{2}=0.05$, and was seen as less rational than the sad message, $F_{(2,412)}=6.74, p<0.001, \eta_{p}^{2}=0.03$.

\section{H1: Predicting Preferences for Emotional Over Non-emotional Messages}

In order to test Hypothesis 1, a multiple linear regression was used to test the unique effects of perceived persuasiveness, matching of feelings, and the three impressions of the speaker (strong, caring, and rational) on preferences for the message framed with emotion over the original, no-emotion message. Participants' relative preference for the emotional message over the no-emotion message was positively related to perceptions of how persuasive the messages were, $B=0.46, p<0.001$, whether the messages matched their feelings, $B=0.17, p<0.001$, and their impressions of the author of the emotional message as rational, $B=0.28, p<0.001$, and as strong, $B=0.10, p=0.01$, $F_{(5,405)}=208.28, p<0.001, R^{2}=0.72$. The extent to which the speaker was perceived as caring did not predict message preferences beyond the other predictor variables in the model. Thus, H1a, H1b, and most of H1c were supported.

\section{H2: Effects of Emotion Type on Impressions}

In order to test Hypothesis $2 \mathrm{a}$ and $2 \mathrm{~b}$, the type of emotion framing (sad, fear, anger) conveyed in the modified message was entered into a MANOVA predicting impressions of the speaker of the emotional message as rational, strong, and caring. Post-hoc tests were conducted using the Bonferroni correction. Impressions of the speaker of the emotional message differed depending upon the type of emotion used. Inconsistent with $\mathrm{H} 2 \mathrm{a}$, emotional messages were seen as more rational than irrational when compared to non-emotional messages, $t_{(414)}=1.20, p=0.05$.
However, as noted above, the degree of perceived rationality of the emotional message depended on the specific emotion used, $F_{(2,412)}=6.78, p<0.001, \eta_{p}^{2}=0.03$. The speaker was perceived as more rational when they conveyed sadness compared to when they conveyed anger $\left(M_{\text {difference }}=1.05, p<0.001\right)$, although perceptions of the rationality of a speaker conveying fear did not differ significantly from either anger or sadness. Thus, H2a was partially supported, in that anger specifically was perceived as more irrational than rational, while other emotional messages (fear and sadness) were perceived as more rational than irrational.

Consistent with $\mathrm{H} 2 \mathrm{~b}$, the speaker of the message was seen as stronger when they conveyed anger compared to sadness $\left(M_{\text {difference }}=1.02, p=0.001\right)$ or fear $\left(M_{\text {difference }}=1.245\right.$, $p<0.001$ ), with the latter two types of emotion not differing from each other, $F_{(2,411)}=10.02, p<0.001, \eta_{p}^{2}=0.05$. Further, the speaker of the message was seen as less caring when they conveyed anger than when they conveyed sadness $\left(M_{\text {difference }}=-1.25, p<0.001\right)$ or fear $\left(M_{\text {difference }}=-0.80\right.$, $p=0.002$ ), with the latter two types of emotion not differing from each other, $F_{(2,411)}=14.91, p<0.001, \eta_{p}^{2}=0.07$. Thus, H2b was supported.

In order to test $\mathrm{H} 2 \mathrm{c}$, we conducted a series of regressions to examine the parallel mediation effects of emotion type on preferences via rationality, strength, and caring, using PROCESS model 4 with 5,000 bootstrap samples and 95\% bias-corrected confidence intervals (Hayes, 2017). The predictor variable was the orthogonal contrast of anger vs. sad and fear messages, controlling for the contrast of sad vs. fear messages ${ }^{4}$ and whether emotions matched participants' feelings, in order to identify the unique mediating effects of impressions. Compared to the sad and fear messages, there was a significant, negative indirect effect of anger framing on preference for the emotion message via impressions of caring, $B=-0.08, S E=0.02,95 \% \mathrm{CI}$ $[-0.14$ to -0.04$]$, and rationality, $B=-0.11, S E=0.07,95 \%$ CI $[-0.20$ to -0.03$]$, and a significant, positive indirect effect of anger framing on preference for the emotion message via impressions of strength, $B=0.25, S E=0.084,95 \%$ CI $[0.17$ to 0.33]. Specifically, framing the message with anger compared to sadness or fear decreased impressions of the message as caring $(B=-0.29, p<0.001)$ and caring increased preference for the message $(B=0.28, p<0.001)$. Framing the message with anger compared to sadness or fear also decreased impressions of the message as rational $(B=-0.18, p<0.01)$ and rationality increased preference for the message $(B=0.64, p<0.001)$. Contrarily, framing the message with anger compared to sadness or fear increased impressions of the message as strong $(B=0.45$, $p<0.001)$ and strength increased preference for the message $(B=0.56, p<0.001)$. Thus, $\mathrm{H} 2 \mathrm{c}$ was supported.

\section{H3: Effects of Participant Gender and Impressions on Preference}

In order to test Hypothesis 3, two separate regressions tested preference for the emotional over the non-emotional message as

${ }^{4}$ The contrast between the fear vs. sad messages were not related to impressions, hence, there was no indirect effects from this contrast to preferences. 
predicted by either (1) gender of the participant X impressions of strength, or (2) gender of the participant X impressions of caring. Neither interaction was significant suggesting that women and men do not differ in what drives their preferences for emotional message framing. Further, participant gender was not directly related to preferences for an emotional message over the nonemotional message. These findings indicate a lack of support for $\mathrm{H} 3 \mathrm{a}$ and $\mathrm{H} 3 \mathrm{~b}$.

\section{H4: Effects of Political Identity on Matched Feelings}

In order to test Hypothesis $4 \mathrm{a}$, political identity (Republican, Independent, or Democrat) and type of emotion framing (anger, sadness, or fear) were entered into an ANOVA to test the extent to which messages matched participants' own feelings about climate change. Post-hoc tests were conducted using the Bonferroni correction. Political identity significantly predicted whether the emotion message matched participants' own emotions about climate change, $F_{(2,389)}=10.76, p<0.001, \eta_{p}^{2}=0.05$, with Democrats $(M=64.82, S E=1.69)$ reporting that the emotion message matched their feelings more than Independents $(M=53.30, S E=2.43)$ or Republicans $(M=53.03, S E=3.12$; Independents and Republicans did not differ from each other). Thus, H4a was partially supported. There was not a significant interaction between political identity and type of emotion framing on whether the emotion message matched participants' feelings about climate change, suggesting that Democrats are more likely than Independents or Republicans to feel sadness, fear, and anger about climate change.

To test $\mathrm{H} 4 \mathrm{~b}$, we conducted a regression to examine the parallel mediation effects of political identity on preferences via matching of feelings, using PROCESS model 4 with 5,000 bootstrap samples and $95 \%$ bias-corrected confidence intervals (Hayes, 2017). Because no differences were found between Independents and Republicans in $\mathrm{H} 4 \mathrm{a}$, the predictor variable was the orthogonal contrast of Democrats vs. Independents and Republicans, controlling for the contrast between Independents and Republicans and impressions of the message, in order to identify the unique mediation effects of matching of feelings. Results showed a significant, positive indirect effect, $B=0.07$, $S E=0.02,95 \%$ CI $[0.03$ to 0.13$]$, such that Democrats were more likely than Independents or Republicans to say that the emotion message matched their feelings more than the nonemotion message, $B=2.25, p<0.001$, and matching of feelings predicted greater preference for the emotional message over the non-emotion message, $B=0.03, p<0.001$. Thus, H4b was supported.

\section{Discussion}

Consistent with general recommendations made in academic and popular literature, participants preferred the nonemotional message to the modified emotional message about climate change. However, the three reasons we tested (perceived persuasiveness, matching feelings, and impression considerations) significantly and independently predicted preference for the climate change message framed with emotion. While recommendations about using negative emotions in climate change communication are usually made under the assumption that they are less persuasive, we specifically found that participants perceived that the emotional messages were more persuasive and the speakers that used sadness and fear in their messages were perceived as more rational, caring, and strong than a message without emotion and speakers that used anger in their messages were perceived as more caring and strong than a message without emotion. Additionally, perceived persuasiveness, strength, and rationality of the speaker, as well as the degree to which emotions matched those felt by participants, contributed favorably to preference for using emotional messages. Thus, there may continue to be reasons to use negative emotions in climate change communication.

Further, the results suggest that preference for using specific emotions in climate change messages may be a result of concerns about impression management. The results demonstrated that beliefs about persuasiveness and matching of the participants' feelings did not differ based on the specific emotions, but that different emotions influenced impressions of the speaker, which in turn influenced preference for conveying the emotion. Specifically, the expression of anger was seen as more strong but less caring and rational compared to the expression of sadness and fear. More strength, in turn, predicted greater preference for the emotional message, while less caring and rationality predicted lesser preference for the emotional message. Thus, anger messages appear to have two opposing effects on preference due to impressions about those who use anger in climate change communication. Further, although it was not significantly different from fear and sadness, the results suggest that the anger condition was least preferred, suggesting that appearing caring and rational may be a more important consideration than appearing strong in individuals' preference for using anger in climate change communication.

Although participants' gender did not predict preferences for the emotional over the non-emotional message, impressions of the emotions were consistent with stereotypically feminine and masculine characteristics (i.e., fear and sadness conveyed caring while anger conveyed strength). Yet it is important to note that these results did not replicate the gender-matching preferences for emotionally-framed messages found in Study 1, which may have been the result of a forced choice rather than a continuous rating of preference used in Study 2. Further, results supported the prediction that Democrats would be most likely to prefer emotional messages over the non-emotion message because emotional messages were more likely to match their feelings, but contrary to expectations, Independents were not more likely than Republicans to say that the emotion messages matched their feelings about climate change. It is possible that Independents are motivated to avoid emotional responses toward climate change because of the strong political polarization of the issue (Dunlap et al., 2016).

\section{STUDY 3}

The general recommendation against using negative emotions in climate change communication posits that these emotions will hinder actions to address climate change that might otherwise occur. In addition, seeing a message as persuasive (i.e., likely to 
change the attitudes or behaviors of others) was one key reason that individuals prefer non-emotional messages over messages framed with negative emotion. Therefore, the primary purpose of Study 3 was to test whether messages framed with sadness, fear, anger, or no emotion differentially influence the likelihood of individuals to take action to address climate change.

We test the effects of gender and political identity on the effectiveness of emotional and non-emotional message framings. Given gender differences in preferences for emotional messages found in Study 1, it is possible that emotional messages would be more effective at prompting action for women than for men. Consistent with this prediction, previous research suggests that women are more persuaded by messages that convey feelings about a topic while men are more persuaded by messages that convey thoughts (Mayer and Tormala, 2010). Study 1 results also suggest that sad messages may be particularly effective for women compared to men. However, given the lack of gender effects in Study 2, we do not make specific predictions about directionality of influence.

Results for the influence of political identity on preferences for emotional messages via matching of feelings in Study 2 were consistent with the under-powered pattern of effects in found in Study 1 suggesting that Democrats have greater preference for emotional messages relative to Republicans. Therefore, we expected that Democrats would be more likely than Republicans to take action to address climate change in general, and that emotional messages would be more likely to prompt action among Democrats than Republicans. However, we did not make predictions about Independents, as they were more similar to Democrats in Study 1 and more similar to Republicans in Study 2.

\section{Materials and Methods \\ Design}

The study consisted of a 2 (participant gender: female, male) X 3 (political party: Democrat, Republican, Independent) $\times$ 4 (emotional framing of message: sadness, fear, anger, no emotion) between-subjects design. The dependent variables were indication of willingness to support a petition for greater EPA mitigation of climate change via signing and sharing it with others, and actual signing of the petition.

\section{Participants}

Participants were 1,254 U.S.-residing adults recruited online from Amazon's Mechanical Turk and paid $\$ 0.50$ for their participation. Like Studies 1 and 2, participants were excluded if they did not identify as belonging to one of the three major U.S. political party groups $(n=115,9.2 \%)$ or if they completed the survey in less than half the median completion time or two times the median completion time (5.03 min; $n=213$ ). Further, participants were not recruited for this study if they had participated in any of the prior studies.

The final sample consisted of 926 participants living in the U.S. (549 women and 377 men), with median age of 30 (range 19 to 77). The majority identified their race/ethnicity as White/Caucasian (81\%), while a minority identified as Black/African American (7\%), Asian (8\%), Latinx (6\%), or another racial/ethnic group (2\%). Just under half the sample indicated that they identified as Democrat (43\%), while 37\% identified as Independent, and $20 \%$ as Republican. Participants leaned toward being liberal (13\% very liberal, 38\%, liberal, $28 \%$ moderate, $17 \%$ conservative, $4 \%$ very conservative). Most participants indicated they were concerned about climate change based upon self-categorization into one of the Six Americas climate change opinion groups (27\% Alarmed, $43 \%$ Concerned, $16 \%$ Cautious, $6 \%$ Disengaged, $4 \%$ Doubtful). Most participants (75\%) had completed between some college, a 2-year degree, or a 4-year college degree, and had a median annual income of between $\$ 30,000$ and $\$ 39,999$.

\section{Procedure and Materials}

As in Study 1 and 2, participants were told they would read a petition that would support the Environmental Protection Agency's (EPA) limit on industrial carbon pollution from coal power plants. Unlike in Study 1 and 2, participants were randomly assigned to one of four the emotion message conditions (sad, fear, anger, or no emotion). The message was nearly identical to that used in Study 2, and was designed to appear as if it was written by a lay person ${ }^{5}$. Participants indicated whether they were willing to sign and share the petition publicly, and asked to actually sign the petition by providing their name. Finally, participants completed dependent measures and demographic information, and were then thanked, debriefed, and compensated.

\section{Measures}

\section{Willingness to support the petition}

A composite scale of willingness to support the petition was created by averaging four items: "Would you be willing to sign the petition?", "Would you be willing to have your name appear on a public website?," "Would you be willing to post this on one of your social media sites?", and "Would you be willing to send this petition to someone you know?" Responses were measured on a four-point scale: 1 (definitely not), 2 (probably not), 3 (probably yes) and 4 (definitely yes), with larger numbers indicating a greater intention to sign the petition (Cronbach's $\alpha=0.91)$.

\section{Actual signing behavior}

Signing behavior was assessed with one item, and was presented to only those participants who indicated that they either would "probably" or "definitely" sign the petition. These participants were asked to provide their first and last name. If participants provided both their first and last name they were considered to have signed the petition. If no name or only their first or last name was indicated, they were not considered to have signed the petition.

\footnotetext{
${ }^{5} \mathrm{~A}$ manipulation check question asked participants to indicate which type of emotion was expressed in the message (sadness, fear, guilt, anger, or no emotion). Although participants were more likely to select the correct emotion by condition than any one of the other options, less than 50\% selected the correct answer, except in the case of the anger condition, where a majority of participants selected the correct answer (62\%). However, because the base (no-emotion) message may have invoked perceptions of emotions due to the expression of strong opinions and description of negative impacts, we did not remove participants based on the manipulation check question.
} 


\section{Gender and political identity}

Participants completed the same measure of political party and gender identification as used in Studies 1 and 2.

\section{Results and Discussion}

We first tested a 2 (Participant gender: female, male) X 3 (Political Identity) $\times 4$ (Emotional framing of message: sad, fear, anger, no emotion) between-subjects ANOVA on support for the petition. Post-hoc tests were conducted using the Bonferroni correction. Democrats $(M=2.76, S E=0.04)$ were more likely than Independents $(M=2.46, S E=0.05$, $p<0.001)$, who were more likely than Republicans $(M=2.01$, $S E=0.06, p<0.001)$, to indicate willingness to support the petition, $F_{(2,902)}=50.31, p<0.001 ; \eta_{p}^{2}=0.10$. There was also an interaction between participant gender and political party on willingness to support the petition, $F_{(2,902)}=2.91$, $p=0.02 ; \eta_{p}^{2}=0.01$, such that Republican men $(M=2.15$, 95\% CI [1.98-2.31]) indicated greater willingness to support the petition than Republican women $(M=1.87,95 \% \mathrm{CI}$ [1.70-2.05]). There were no other significant gender differences. Importantly, the emotional or non-emotional framing of the message did not influence willingness to support the petition.

Next, we conducted a hierarchical logistic regression to test the effects of participant gender, political identity, and emotional framing of the message on actual signing behavior. Main effects were entered in block 1, two-way interactions were entered in block 2, and the three-way interaction was entered on block 3 . Results indicated that only block 1 was significant, omnibus $X^{2}$ (6) $=83.49, p<0.001$, Nagelkerke $R^{2}=0.12$, and no interactions were significant. Political party significantly predicted signing the petition, Wald $(d f=2)=65.57, p<0.001$, with Democrats over 4 times more likely to sign the petition than Independents or Republicans, Wald $(d f=1)=59.82, p<0.001, O R=4.40$ [95\% CI: 3.02-6.41], and Independents almost two times more likely to sign the petition as Republicans Wald $(d f=1)=11.36$, $p<0.001, O R=1.92$ [95\% CI: 1.31-2.81]. There was also a main effect of participant gender, Wald $(d f=1)=13.90$, $p<0.001$, such that men were almost twice as likely to sign the petition as women, $O R=1.71$ [95\% CI: 1.29-2.26]. Again, there were no effects of emotional framing on actual signing behavior.

Results from Study 3 indicate that framing a message about climate change with negative emotions does not reduce (or increase) behavioral willingness to support the issue or taking action via signing a petition. This key finding is important for recommendations regarding the use of negative emotions in climate change communication, and suggests that while experts and the general public may view climate change messages as more persuasive on behavior when framed without emotion, using negative emotions does not change individual behavior. We did, however, find that political identity was related to willingness and actual signing behavior, consistent with the literature on political orientation and climate change action (e.g., see Dunlap et al., 2016; Leiserowitz et al., 2018).

\section{GENERAL DISCUSSION}

Across three studies of climate change communications framed with or without negative emotions, it appears that the American public largely prefers messages that are framed without emotion, but that the use of negative emotions do not actually dissuade individuals from supporting action on climate change. Further, emotional communications are seen as more persuasive, more likely to reflect the feelings of individuals, and more likely to create impressions about a speaker's caring (except in the case of anger), strength and rationality, all of which also contribute to preferences for using negative emotions. Thus, the larger debate about avoiding negative emotions in climate change communications may be a product of concerns about the impressions negative emotions create about the speaker than about the actual effectiveness of the message on the audience. The results from Study 2 suggest that preferences for non-emotional framing of climate change messages are driven by social desirability concerns perhaps even more so than perceived effectiveness. Although perceived persuasiveness was associated with message preferences, and participants perceived the emotional messages as more persuasive than the nonemotional messages, they still preferred the non-emotional message over the emotional messages. We therefore conclude that conveying negative emotions about climate change when communicating information to others can be beneficial for creating impressions about the speaker and when individuals want to express their emotions, particularly since using these emotions does not reduce others' likeliness of taking action to address climate change.

We found mixed support for the influence of gender on preferences for using negative emotions. In Study 1, men were less likely than women to select messages framed with "feminine" emotions compared to messages without emotion, yet we did not find these same effects in Study 2. Plus, contrary to research on the influence of prescriptive gender stereotypes (Diekman and Eagly, 2008), we did not find that messages framed with stereotypically-feminine or masculine emotions resulted in differences between women and men for willingness to sign the petition. Although some research has indicated that women are more or as likely as men to sign public petitions (Dietz et al., 1998; Norris et al., 2004), other research suggests that women are less likely to feel confident about using the internet (Hargittai and Shafer, 2006), and are less likely to engage in prosocial behavior when the behavior is seen as assertive or risky (e.g., see Eagly, 2009). This is further supported by the finding that men were not more likely than women to indicate willingness to support the petition (except among Republican men and women). Thus, gender differences could have resulted from the fact that the petition signing behavior was online, and women may have been more concerned than men that their names or contact information would be posted publicly. Therefore, the gendered preference for using negative emotions in climate change communication may require further exploration into the situational constraints and types of behaviors measured.

Finally, the results across three studies support prior research on the influence of political identity on emotions and engagement 
related to climate change. Democrats were more likely than Independents or Republicans to indicate that negative emotional messages matched their feelings about climate change, to prefer messages framed with negative emotions, and to support and sign the petition to address climate change. This is consistent with other findings that Democrats are more concerned about climate change and are the political group most likely to take action to address climate change (Leiserowitz et al., 2018). While our results also reflected prior findings that Independents generally fall in between Democrats and Republicans in their willingness to address climate change, we unexpectedly found that Independents were just as unlikely as Republicans to prefer messages about climate change framed with emotion. One possible explanation for this finding is that Independents are more hesitant to weigh in on conversations about climate change than Democrats, particularly if it is seen as a partisan issue, and Independents are motivated to appear non-partisan (Dunlap et al., 2016). However, because the majority of investigations into the political partisanship of climate change primarily analyze the difference between Democrats and Republicans, this finding and explanation warrants further investigation.

\section{Limitations and Future Directions}

The primary limitation of the current research is that we tested communications framed with negative emotions (i.e., language that expressed negative emotional feelings by the author) as opposed to messages that are intended to invoke negative emotions in the reader. We did not attempt to manipulate, nor did we measure, whether the framing of the message changed the emotional state of the participants. The academic and popular consensus around avoiding negative emotions in climate change communication primarily bases this recommendation off of assumptions that creating a negative emotional state among members of the general public will inhibit behavioral responses (e.g., see Moser, 2007). Therefore, individuals may avoid expressing negative emotions, even though it is unclear to what extent using negative emotional tones in one's own communication about climate change impacts the emotions of others. Thus, we were interested in exploring the former phenomenon rather than the latter, to understand both the benefits and drawbacks to personally using emotions in one's own communications about climate change. While our findings suggest that expressing negative emotions about climate does not create behavioral inhibition, we are limited in our ability to make recommendations about messages which invoke a strong negative emotional state in readers/listeners, as it is still possible that this might diminish their inclination to address climate change behaviorally. Further, we provided an immediate and direct avenue for taking action to address climate change (sending a petition), which may also have helped to alleviate behavioral inhibitions due to the feeling that participants lacked personal or collective efficacy.

Another limitation is that we only tested signing a petition as a measure of behavioral response to addressing climate change. We choose this behavior because it is argued to be one of the more unlikely but also more impactful forms of personal pro-environmental behavior (e.g., see Stern, 2000) and it presented fewer barriers to engagement such as lack of skills or resources. However, the nature of signing an online petition is public, direct, and allows others to see one as a climate change activist. Therefore, people who care about the issue of climate change but who do not want to experience public scrutiny or confrontation may have been resistant to engaging in this behavior. In particular, this may have been important for the gender and political identity effects found in Study 3: that is, women and Independents/Republicans may be more likely to engage in a less-conspicuous behavior to address climate change, such as anonymously donating money. Thus, these results should be replicated and include tests of other types of behavioral engagement.

All three studies were conducted between 2014 and 2016 during the Obama presidency and the EPA plan to cut carbon emissions that was summarized for participants described the actual plan put forth by the Obama administration. Participants in Study 3 were directed to the actual EPA site at which they could submit their comments. All data was collected before Trump was elected to office and the priorities of the EPA were shifted. Thus, the type and strength of emotions felt by the public regarding climate change may be different under the current presidential administration, and future research may illuminate the degree to which current political discourse shapes whether and how negative emotions are used to communicate about climate change and influence individuals to take action.

\section{Conclusions}

Many scholars and commentary in public media recommend avoiding negative emotional framing of climate change information due to the potential lack of effectiveness of negative emotional frames. Consistent with this logic, respondents were less likely to prefer emotional over non-emotional framing of climate change messages. However, this preference may lead members of the public to suppress their emotions when communicating about climate change. Despite gendered associations with emotions we did not find consistent evidence that preferences varied by gender nor that the gendered impressions conveyed by the emotions differentially affected women and men. In contrast, political identity was related to the preference for expressing negative emotions related to climate change with Democrats preferring emotional messages more than Republicans and Independents because negative emotions were more likely to match their feelings about climate change, which may be a result of Democrats being more concerned about climate change (Leiserowitz et al., 2018). However, the results suggest that there are impression management benefits to using negative emotions in climate change messaging, and that expressing negative emotions does not hinder others' likelihood of signing a public petition to address climate change.

\section{ETHICS STATEMENT}

This study was carried out in accordance with the recommendations of the Pennsylvania State University 
Institutional Review Board for research with human subjects. All subjects gave written informed consent in accordance with the Declaration of Helsinki. The protocol was approved by the Pennsylvania State University Institutional Review Board.

\section{DATA AVAILABILITY STATEMENT}

The raw data supporting the conclusions of this manuscript will be made available by the authors, without undue reservation, to any qualified researcher.

\section{REFERENCES}

Anderson, C. A., Shibuya, A., Ihori, N., Swing, E. L., Bushman, B. J., Sakamoto, A., et al. (2010). Violent video game effects on aggression, empathy, and prosocial behavior in Eastern and Western countries: a meta-analytic review. Psychol. Bull. 136:151. doi: 10.1037/a0018251

Bashir, N. Y., Lockwood, P., Chasteen, A. L., Nadolny, D., and Noyes, I. (2013). The ironic impact of activists: negative stereotypes reduce social change influence. Eur. J. Soc. Psychol. 43, 614-626. doi: 10.1002/ejsp. 1983

Bockarjova, M., and Steg, L. (2014). Can Protection Motivation Theory predict pro-environmental behavior? Explaining the adoption of electric vehicles in the Netherlands. Glob. Environ. Change 28, 276-288. doi: 10.1016/j.gloenvcha.2014.06.010

Bosson, J. K., Vandello, J. A., Burnaford, R. M., Weaver, J. R., and Arzu Wasti, S. (2009). Precarious manhood and displays of physical aggression. Personal. Soc. Psychol. Bull. 35, 623-634. doi: 10.1177/0146167208331161

Bower, G. H. (1981). Mood and memory. Am. Psychol. 36:129. doi: 10.1037/0003-066X.36.2.129

Brady, W. J., Wills, J. A., Jost, J. T., Tucker, J. A., and Van Bavel, J. J. (2017). Emotion shapes the diffusion of moralized content in social networks. Proc. Nat. Acad. Sci. U.S.A. 114, 7313-7318. doi: 10.1073/pnas.1618923114

Cameron, C. D., and Payne, B. K. (2011). Escaping affect: how motivated emotion regulation creates insensitivity to mass suffering. J. Pers. Soc. Psychol. 100, 1-15. doi: $10.1037 / \mathrm{a} 0021643$

Cameron, J., Weingraub, A., Schwarzennegger, M., Wilhelm, J., Bach, D., and Gelber (Producers). (2014). The Years of Living Dangerously [Motion Picture]. Los Angeles, CA: Showtime.

Cismaru, M., Cismaru, R., Ono, T., and Nelson, K. (2011). "Act on climate change": an application of protection motivation theory. Soc. Mar. Q. 17, 62-84. doi: $10.1080 / 15245004.2011 .595539$

Czopp, A. M. (2013). The passive activist: negative consequences of failing to confront antienvironmental statements. Ecopsychology 5, 17-23. doi: 10.1089/eco.2012.0066

Dalgleish, T., Yiend, J., Schweizer, S., and Dunn, B. D. (2009). Ironic effects of emotion suppression when recounting distressing memories. Emotion 9:744. doi: 10.1037/a0017290

Diekman, A. B., and Eagly, A. H. (2000). Stereotypes as dynamic constructs: women and men of the past, present, and future. Person. Soc. Psychol. Bull. 26, 1171-1188. doi: 10.1177/0146167200262001

Diekman, A. B., and Eagly, A. H. (2008). "Of men, women, and motivation," in Handbook of Motivation Science, eds J. Y. Shah and W. L. Gardner (New York, NY: The Guilford Press), 434-447.

Diekman, A. B., and Goodfriend, W. (2006). Rolling with the changes: a role congruity perspective on gender norms. Psychol. Women Q. 30, 369-383. doi: 10.1111/j.1471-6402.2006.00312.x

Dietz, T., Stern, P. C., and Guagnano, G. A. (1998). Social structural and social psychological bases of environmental concern. Environ. Behav. 30, 450-471. doi: $10.1177 / 001391659803000402$

Dunlap, R. E. (2014). Global Warming or Climate Change: Is There a Difference? Gallup. Available online at: http://www.gallup.com/poll/168617/ global-warming-climate-change-difference.aspx

Dunlap, R. E., McCright, A. M., and Yarosh, J. H. (2016). The political divide on climate change: partisan polarization widens in the US. Environment 58, 4-23. doi: $10.1080 / 00139157.2016 .1208995$

\section{AUTHOR CONTRIBUTIONS}

All authors listed have made a substantial, direct and intellectual contribution to the work, and approved it for publication.

\section{SUPPLEMENTARY MATERIAL}

The Supplementary Material for this article can be found online at: https://www.frontiersin.org/articles/10.3389/fcomm. 2018.00063/full\#supplementary-material

Eagly, A. H. (2009). The his and hers of prosocial behavior: an examination of the social psychology of gender. Am. Psychol. 64:644. doi: 10.1037/0003-066X.64.8.644

Engelhaupt, E. (2017). Does Doom and Gloom Convince Anyone About Climate Change? ScienceNews. Available online at: https://www.sciencenews.org/blog/ science-public/new-york-magazine-climate-change

Fan, R., Zhao, J., Chen, Y., and Xu, K. (2014). Anger is more influential than joy: Sentiment correlation in Weibo. PLoS ONE 9:e110184. doi: 10.1371/journal.pone.0110184

Feinberg, M., and Willer, R. (2011). Apocalypse soon? Dire messages reduce belief in global warming by contradicting just-world beliefs. Psychol. Sci. 22, 34-38. doi: $10.1177 / 0956797610391911$

Fielding, K. S., and Hornsey, M. J. (2016). A social identity analysis of climate change and environmental attitudes and behaviors: insights and opportunities. Front. Psychol. 7:121. doi: 10.3389/fpsyg.2016.00121

Fischer, A. H. (1993). Sex differences in emotionality: fact or stereotype? Fem. Psychol. 3, 303-318. doi: 10.1177/0959353593033002

Flett, G. L., Blankstein, K. R., Pliner, P., and Bator, C. (1988). Impression-management and self-deception components of appraised emotional experience. Br. J. Soc. Psychol. 27, 67-77. doi: 10.1111/j.2044-8309.1988.tb00805.x

Floyd, D. L., Prentice Dunn, S., and Rogers, R. W. (2000). A meta-analysis of research on protection motivation theory. J. Appl. Soc. Psychol. 30, 407-429. doi: 10.1111/j.1559-1816.2000.tb02323.x

Fraser, J., Pantesco, V., Plemons, K., Gupta, R., and Rank, S. J. (2013). Sustaining the conservationist. Ecopsychology 5, 70-79. doi: 10.1089/eco.2012.0076

Hansen, J. W., Marx, S. M., and Weber, E. U. (2004). The Role of Climate Perceptions, Expectations, and Forecasts in Farmer Decision Making: The Argentine Pampas and South Florida: Final Report of an IRI Seed Grant Project. Final report of an IRI seed grant project: International Research Institute for Climate Prediction; Columbia University, Palisades, NY. Available online at: https://academiccommons.columbia.edu/doi/10.7916/D8N01DC6

Hareli, S., and Hess, U. (2010). What emotional reactions can tell us about the nature of others: an appraisal perspective on person perception. Cogn. Emot. 24, 128-140. doi: 10.1080/02699930802613828

Hareli, S., and Hess, U. (2012). The social signal value of emotions. Cogn. Emot. 26, 385-389. doi: 10.1080/02699931.2012.665029

Hargittai, E., and Shafer, S. (2006). Differences in actual and perceived online skills: the role of gender. Soc. Sci. Q. 87, 432-448. doi: 10.1111/j.1540-6237.2006.00389.x

Hart, P. S., and Nisbet, E. C. (2012). Boomerang effects in science communication: how motivated reasoning and identity cues amplify opinion polarization about climate mitigation policies. Communic. Res. 39, 701-723. doi: 10.1177/0093650211416646

Hayes, A. F. (2017). Introduction to Mediation, Moderation, and Conditional Process Analysis: A Regression-Based Approach. New York, NY: Guilford Publications.

Higgins, E. T., and Pittman, T. S. (2008). Motives of the human animal: comprehending, managing, and sharing inner states. Annu. Rev. Psychol. 59:361-85. doi: 10.1146/annurev.psych.59.103006.093726

Hornsey, M. J., and Fielding, K. S. (2016). A cautionary note about messages of hope: focusing on progress in reducing carbon emissions weakens mitigation motivation. Global Environ. Change 39, 26-34. doi: 10.1016/j.gloenvcha.2016.04.003 
Hornsey, M. J., Fielding, K. S., McStay, R., Reser, J. P., Bradley, G. L., and Greenaway, K. H. (2015). Evidence for motivated control: Understanding the paradoxical link between threat and efficacy beliefs about climate change. $J$. Environ. Psychol. 42, 57-65. doi: 10.1016/j.jenvp.2015.02.003

Hornsey, M. J., Harris, E. A., Bain, P. G., and Fielding, K. S. (2016). Meta-analyses of the determinants and outcomes of belief in climate change. Nat. Clim. Chang. 6:622-626. doi: 10.1038/nclimate2943

Keshavarz, M., and Karami, E. (2016). Farmers' pro-environmental behavior under drought: application of protection motivation theory. J. Arid Environ. 127, 128-136. doi: 10.1016/j.jaridenv.2015.11.010

Kim, S., Jeong, S.-H., and Hwang, Y. (2013). Predictors of pro-environmental behaviors of American and Korean students: the application of the theory of reasoned action and protection motivation theory. Sci. Commun. 35, 168-188. doi: $10.1177 / 1075547012441692$

Kluger, J. (2006). Global Warming Heats up. Time Magazine. Available online at: https://content.time.com/time/magazine/article/0,9171,1176980,00.html

Leiserowitz, A., Maibach, E., Roser-Renouf, C., Rosenthal, S., Cutler, M., and Kotcher, J. (2018). Politics \& Global Warming, March 2018. Yale University and George Mason University, Yale Program on Climate Change Communication, New Haven, CT.

Maibach, E., Roser-Renouf, C., and Leiserowitz, A. (2009). Global Warming's Six Americas 2009: An Audience Segmentation Analysis. Fairfax, VA: Retrieved from Center for Climate Change Communication. Available online at: http://www.climatechangecommunication.org/wp-content/uploads/ 2016/03/2009-Global-Warmings-Six-Americas.pdf

Markowitz, E., Slovic, P., Vastfjall, D., and Hodges, S. (2013). Compassion fade and the challenge of environmental conservation. Judgm. Decis. Mak. 8, 397-406.

Mayer, N. D., and Tormala, Z. L. (2010). "Think" versus "feel" framing effects in persuasion. Person. Soc. Psychol. Bull. 36, 443-454. doi: 10.1177/0146167210362981

McCright, A. M., and Dunlap, R. E. (2011). The politicization of climate change and polarization in the American public's views of global warming, 2001-2010. Sociol. Q. 52, 155-194. doi: 10.1111/j.1533-8525.2011.01198.x

Moser, S. C. (2007). "More bad news: the risk of neglecting emotional responses to climate change information,: in Creating a Climate for Change: Communicating Climate Change and Facilitating Social Change, eds S. C. Moser and L. Dilling (New York, NY: Cambridge University Press), 64-80. doi: 10.1017/CBO9780511535871.006

Moser, S. C., and Dilling, L. (2011). "Communicating climate change: closing the science-action gap," in The Oxford Handbook of Climate Change and Society, eds J. S. Dryzek, R. B. Norgaard, and D. Schlosberg (New York, NY: Oxford University Press), 161-174. doi: 10.1093/oxfordhb/9780199566600.003.0011

Moyer, B., MacAllister, J., and Soifer, M. L. F. S. (2001). Doing Democracy: The MAP Model for Organizing Social Movements. Gabriola Island, BC: New Society Publishers.

Nelson, J. A. (2015). Fearing fear: gender and economic discourse. Mind Soc. 14, 129-139. doi: 10.1007/s11299-014-0148-6

Nordhaus, T., and Shellenberger, M. (2014). Global Warming Scare Tactics. New York Times, 8. Available online at: https://www.nytimes.com/2014/04/09/ opinion/global-warming-scare-tactics.html

Norris, P., Lovenduski, J., and Campbell, R. (2004). Gender and Political Participation. London: The Electoral Commission.

O'Neil, J. M. (1981). Patterns of gender role conflict and strain: sexism and fear of femininity in men's lives. Pers. Guid. J. 60, 203-210. doi: 10.1002/j.2164-4918.1981.tb00282.x

O'Neill, S., and Nicholson-Cole, S. (2009). "Fear won't do it:" Promoting positive engagement with climate change through visual and iconic representations. Sci. Commun. 30, 355-379. doi: 10.1177/1075547008329201

Parkinson, B. (1996). Emotions are social. Br. J. Psychol. 87, 663-683. doi: 10.1111/j.2044-8295.1996.tb02615.x

Pratkanis, A. R., and Turner, M. E. (1996). Persuasion and democracy: strategies for increasing deliberative participation and enacting social change. J. Soc. Issues 52, 187-205. doi: 10.1111/j.1540-4560.1996.tb01369.x

Richards, J. M., and Gross, J. J. (1999). Composure at any cost? The cognitive consequences of emotion suppression. Person. Soc. Psychol. Bull. 25, 1033-1044. doi: 10.1177/01461672992511010

Ridderinkhof, K. R. (2017). Emotion in action: A predictive processing perspective and theoretical synthesis. Emot. Rev. 9, 319-325. doi: $10.1177 / 1754073916661765$
Roser-Renouf, C., Stenhouse, N., Rolfe-Redding, J., Maibach, E., and Leiserowtiz, A. (2014). "Engaging diverse audiences with climate change: message strategies for global warming's six Americas," in Handbook of Environment and Communication, eds A. Hanson and R. Cox (New York, NY: Routledge), 368-386.

Rozin, P., and Royzman, E. B. (2001). Negativity bias, negativity dominance, and contagion. Person. Soc. Psychol. Rev. 5, 296-320. doi: 10.1207/S15327957PSPR0504_2

Rudman, L. A., and Fairchild, K. (2004). Reactions to counterstereotypic behavior: the role of backlash in cultural stereotype maintenance. J. Pers. Soc. Psychol. 87, 157-176. doi: 10.1037/0022-3514.87.2.157

Schlenker, B. R. (1980). Impression Management. Monterey, CA: Brooks/Cole Publishing Company.

Schwarz, N. (2000). Emotion, cognition, and decision making. Cogn. Emot. 14, 433-440. doi: 10.1080/026999300402745

Schwarz, N., and Clore, G. L. (1996). Feelings and phenomenal experiences. Soc. Psychol. 2, 385-407.

Shields, S. (2002). Speaking from the Heart: Gender and the Social Meaning of Emotion. Cambridge, UK: Cambridge University Press.

Shields, S. (2013). Gender and emotion: what we think we know, what we need to know, and why it matters. Psychol. Women Q. 37, 423-435. doi: 10.1177/0361684313502312

Shome, D., and Marx, S. (2009). The Psychology of Climate Change Communication: A Guide for Scientists, Journalists, Educators, Political Aides, and the Interested Public [Press release]. Available online at: https://pure.uva.nl/ws/files/928230/ 79652_315602.pdf

Simon, R. W., and Nath, L. E. (2004). Gender and emotion in the United States: do men and women differ in self-reports of feelings and expressive behavior? Am. J. Soc. 109, 1137-1176. doi: 10.1086/382111

Stern, P. C. (2000). New environmental theories: toward a coherent theory of environmentally significant behavior. J. Soc. Issues 56, 407-424. doi: 10.1111/0022-4537.00175

Swim, J. K., and Bloodhart, B. (2014). Portraying the perils to polar bears: the role of empathic and objective perspective-taking toward animals in climate change communication. Environ. Commun. 9, 446-468. doi: 10.1080/17524032.2014.987304

Swim, J. K., and Geiger, N. (2017). From alarmed to dismissive of climate change: a single item assessment of individual differences in concern and issue involvement. Environ. Commun. 11, 568-586. doi: 10.1080/17524032.2017.1308409

Swim, J. K., and Geiger, N. (2018). The gendered nature of stereotypes about climate change opinion groups. Group Process. Intergroup Relat. 21, 438-456. doi: $10.1177 / 1368430217747406$

Swim, J. K., Geiger, N., Sweetland, J., and Fraser, J. (2018a). "Social construction of scientifically grounded climate change discussions," in Psychology and Climate Change, eds S. Clayton and C. Manning (London: Elsevier), 65-93. doi: 10.1016/B978-0-12-813130-5.00004-7

Swim, J. K., Vescio, T. K., Dahl, J. L., and Zawadzki, S. J. (2018b). Gendered discourse about climate change policies. Glob. Environ. Change 48, 216-225. doi: 10.1016/j.gloenvcha.2017.12.005

Van Zomeren, M. (2013). Four core social-psychological motivations to undertake collective action. Soc. Personal. Psychol. Compass 7, 378-388. doi: $10.1111 /$ spc3.12031

Weber, E. U. (2010). What shapes perceptions of climate change? Wiley Interdiscipl. Rev. Clim. Change 1, 332-342. doi: 10.1002/wcc.41

Wrede, O., Ask, K., and Strömwall, L. A. (2015). Sad and exposed, angry and resilient? Soc. Psychol. 46, 55-64. doi: 10.1027/1864-9335/a000221

Conflict of Interest Statement: The authors declare that the research was conducted in the absence of any commercial or financial relationships that could be construed as a potential conflict of interest.

Copyright (c) 2019 Bloodhart, Swim and Dicicco. This is an open-access article distributed under the terms of the Creative Commons Attribution License (CC BY). The use, distribution or reproduction in other forums is permitted, provided the original author(s) and the copyright owner(s) are credited and that the original publication in this journal is cited, in accordance with accepted academic practice. No use, distribution or reproduction is permitted which does not comply with these terms. 